\title{
Intraventricular microdialysis: a new method for determining monoamine metabolite concentrations in the cerebrospinal fluid of freely moving rats
}

\author{
J1ll B Becker, Frank Adams and Terry E Robinson \\ The Unversity of Michigan, Department of Psychology, Neurosctence Laborator, Bulding, Ann Arbor MI (US 4 )
}

(Recelved 30 September 1987)

(Revised 6 January 1988)

(Accepted 8 February 1988)

Key words Cerebrospinal fluıd, Dopamine metabolite, Microdialysis, Monoamıne metabolite, Haloper1dol, Probenecid, Adrenal medulla graft

\begin{abstract}
A new method is described to estımate the cerebrospinal fluid (CSF) concentrations of monoamine metabolites (dihydroxyphenylacetic acid (DOPAC) homovanullic acid (HVA) and 5-hydroxyindoleacetic acid (5-HIAA)) in the lateral ventricle of freely moving rats by use of in vivo microdialysis Both the baseline concentrations of these metabolites and the rate of dopamine (DA) turnover (estımated by the accumulation of total DA metabolites after $200 \mathrm{mg} / \mathrm{kg}$ probenecid) were within the range reported when other methods were used to sample CSF A series of prelıminary studies were conducted to demonstrate that this method can be used to repeatedly sample CSF, and to show that the method is sensitive to local changes in dopaminergic activity induced by lesions, drugs or grafts (1) Unilateral 6-hydroxydopamine (6-OHDA) lesions of the substantia nigra produced a significant decrease in the CSF concentrations of DOPAC and HVA ipsilateral to the lesion, relative to the contralateral side or to concentrations in anımals without lesions (2) When left and right lateral ventricles were sampled simultaneously in animals with a unılateral 6-OHDA lesion halopendol induced an increase in DOPAC and HVA concentrations in CSF on both sides of the brain Interestingly, the halopendol-induced increase in CSF concentrations of DA metabolites was greater adjacent to the intact striatum of rats with unilateral 6-OHDA lesions than in animals with no lesion (3) Finally, in animals with adrenal medulla tissue grafted into the lateral ventricle there was an increase in the CSF concentration of DOPAC compared to pregraft values or to those of anımals with control grafts
\end{abstract}

\section{Introduction}

The concentrations of dihydroxyphenylacetic acid (DOPAC), homovanillic acid (HVA) and 5hydroxyındoleacetic acid (5-HIAA) in cerebrosp1nal fluid (CSF) are frequently used as indirect indices of brain monoamine activity (Nielsen and Moore, 1982, Nielsen et al, 1983, Hutson et al, 1984a, b, Mignot and Laude, 1985) However, our knowledge of how monoamine metabolites in the

Correspondence J B Becker, The University of Michıgan, Department of Psychology Neuroscience Laboratory Building, 1103 E Huron St, Ann Arbor, MI, 48104-1687, U S A
CSF relate to brain monoamine activity is very incomplete, in part because the methods avallable for sampling CSF are either technically cumbersome, or have other disadantages For example, push-pull perfusion has been used to repeatedly sample the lateral ventricles (Nielsen and Moore, 1982), but (1) extended push-pull experıments are technically difficult because of problems in maintaining an exact balance between the inflow and outflow lines for long periods of time, and the consequences of even brief blockage can be disastrous, and (2) it is difficult to accurately estimate CSF concentrations of metabolites with this method because the CSF obtained from the "pull" cannula is greatly diluted by the effluent from the 
"push" cannula A second method involves withdrawing CSF using a siphoning system (Sarnd et al, 1983, Kornhuber et al , 1986, De La Rıva and Yeo, 1985, Mignot and Laude, 1985), but frequent withdrawal of CSF without replacing fluid may be problematic because of resultant changes in intracerebral pressure Finally, the repeated sampling of multiple sites simultaneously is difficult with previous methods

In this paper a microdialysis technique is described for the repeated sampling of monoamine metabolites in the CSF of freely moving anımals. over extended periods of time (see Ungerstedt, 1984 for a review of microdialysis) This method has a number of advantages over previous methods (1) With microdialysis no fluids are introduced or withdrawn from the ventricle, so changes in intracerebral pressure are munimized (2) More than one site within the ventricular system of an anımal can be sampled at the same tıme without increasing the risk or discomfort to the animal (3) The dialysis probes can be inexpensively constructed from readıly avallable materials, and are reusable (4) Sterility can be maintained because bacteria do not cross the dialysis membrane (5) Many samples can be collected in succession (6) Finally, by calculating recovery in vitro prior to an experiment, it is possible to control for variability among probes and to obtain a relatively accurate estimate of the absolute concentrations of monoamine metabolites in CSF

\section{Methods}

\section{Subjects}

Adult female Long-Evans rats (Charles Ruver Breeders) were housed individually with food and water freely avalable The lights in the anımal colony were maintained on a 1410 (light dark) cycle, lights on at $0800 \mathrm{~h}$ All experiments were conducted between 12.00 and $1800 \mathrm{~h}$

\section{Surgery}

For the experiments with freely moving animals guide cannulae constructed from 18 gauge thin wall stainless steel tubing were implanted stereotaxically above the lateral ventricle, $1 \mathrm{~mm}$ ventral from skull surface Some animals also received a unilateral 6-OHDA lesion of the substantid nigra at this time, as described previously (Robinson et dl, 1982) For the acute experiments anımals received 6-OHDA lesions but guide cannulae were not implanted All anımals were allowed d mınımum of 4 weeks for recovery prior to intraventricular microdialysis

\section{Construction of the microdialysis probe}

The microdialysis probe consisted of a reusable assembly with a single-use microdialysis membrane that was attached to the assembly prior to each dialysis Stainless steel tubing (33 gauge 30 $\mathrm{cm}, 20$ gauge $8 \mathrm{~mm}$ and 25 gauge thin wall 17 $\mathrm{mm}$ ) was cut to the lengths indicated, degreased and acid etched to roughen the outer surfaces $A$ $75 \mathrm{~cm}$ piece of $067 \mathrm{~mm}$ inside diameter (1 d) microline tubing was washed in methanol and the surface gloss removed by roughenıng dbout $2 \mathrm{~cm}$ of one end with an emery board

The microdialysis assembly is illustrated schematically in Fig 1 and was constructed as follows A 26 gauge needle was inserted into the lumen of the microline tubing ( Fig $1 \mathrm{~L}$ ) and then angled to pierce through the wall about $1 \mathrm{~cm}$ from the roughened end The 33 gauge tubing ( $F_{1}$ 1M) was threaded through the needle and the needle was withdrawn leaving the 33 gauge tubing in place The 25 gauge tubing (F1g $1 \mathrm{H}$ ) was inserted so that exactly $10 \mathrm{~mm}$ of 25 gauge tubing protruded from the end of the microline tubing The 33 gauge tubing extended through the 25 gauge tubing and protruded exactly $35 \mathrm{~mm}$ This arrangement was then secured using 2-Ton epoxy (Fig 1G) When the epoxy had dried the 20 gauge tubing (Fig 1I) was placed over the 25 gauge tubing and epoxied flush with the microline tubing This is the basic unit of the dialysis assembly The epoxy was allowed to cure completely before proceeding To protect the 33 gauge tubing, 025 mm id microline tubing ( $F_{1}$ 1F) was threaded over the stainless steel tubing The entire assembly end of the dialysis probe was then coated with epoxy as indicated in Fig 1 by the dotted line After the epoxy had cured a $5 \mathrm{~mm}$ piece of sulastic tubing $(0625 \mathrm{~mm} 1 \mathrm{~d})$ was applied over the epoxied end of the microline tubing (not shown) 


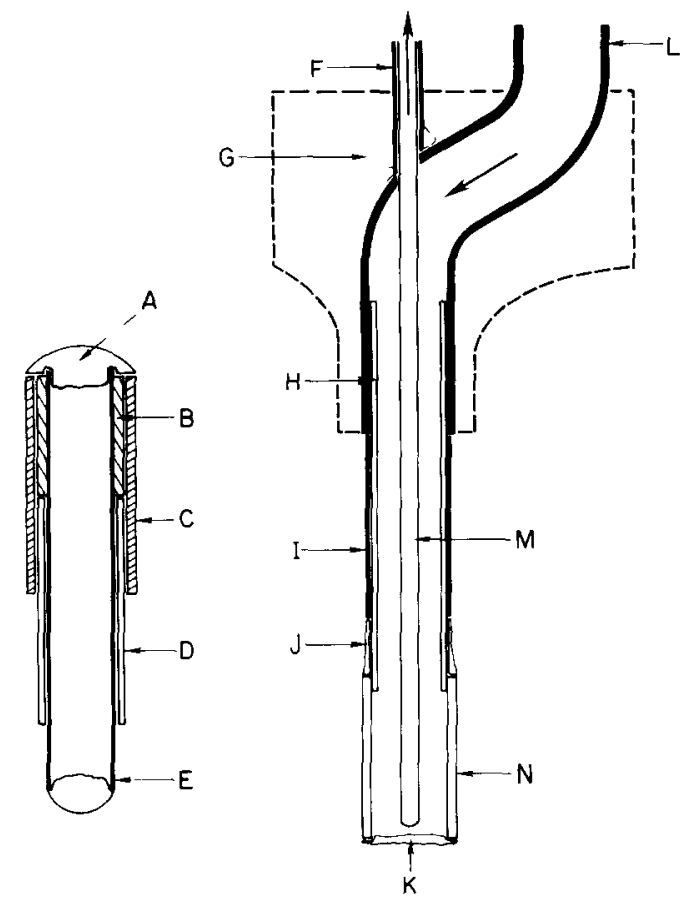

Fig 1 Schematic diagram of the guide cannula/stylet and microdialysis probe for intraventricular microdialysis (not drawn to scale) The 18 gauge (thin wall) guide cannula (D) is closed with a stylet constructed from 20 gauge tubing (E) that is beveled and sealed with epoxy The stylet is fixed in position by 18 gauge tubing (B) crimped over the end and tygon tubing (C) to seal the connection between guide and stylet The top opening of the stylet is sealed with epoxy (A) The dialysis probe consists of a reuseable assembly and a replaceable dialysis membrane $(\mathrm{N})$ (Construction and components described in detall in the text ) Fluid enters va microline tubing (L) and exits via 33 gauge tubing (F)

A length of hollow fiber dialysis tubing (polysulfone, $650 \mu \mathrm{m} \mathrm{od}, 500 \mu \mathrm{m} 1 \mathrm{~d}$, MW cut off 3000 ) approximately $12 \mathrm{~mm}$ long was held under a dissecting scope and the closed tips of a pair of No 5 Dumont forceps were inserted in one end of the fiber about $2 \mathrm{~mm}$ The membrane was stretched slightly by allowing the forceps to open Then, the dialysis fiber was slipped over the 25 gauge tubing and tacked in place with 5-Min epoxy (Fig 1J) One hour later a razor blade was used to cut the dialysis membrane to a length of $4 \mathrm{~mm}$ (from the end of the $25 \mathrm{~g}$ stannless steel cannula), leaving the $33 \mathrm{~g}$ tubing recessed from the end of the dialysis tubing 5-Min epoxy was mixed thoroughly and allowed to cure for $35 \mathrm{~min}$ The end surface of the dialysis tubing was coated with epoxy and strings of epoxy were drawn over the septum until the end of the tube was closed off (Fig 1K) After this had cured 2-Ton epoxy was layered over the 5-Min epoxy on the tip of the probe, to make the epoxy seal water resistant Probes were tested the next day by gently pushing filtered water $(02 \mu \mathrm{m}$ filters) through the microline tubing If liquid emerged from the 33 gauge stainless steel tubing. the probe was viable Probes were stored in $04 \%$ hypochlonte in the refrigerator until needed Prior to use, the probes were thoroughly flushed with filtered water in order remove the glycerın that permeates the dialysis fiber

\section{Intraventricular microdialysis}

An artificial CSF was prepared fresh daily in bolled HPLC grade water $(2 \%$ sodium bicarbonate, $2 \mathrm{mM}$ phosphoric acid with $1200 \mathrm{mM}$ $\mathrm{NaCl}, 125 \mathrm{mM} \mathrm{CaCl}_{2}, 48 \mathrm{mM} \mathrm{KCl}$, and $12 \mathrm{mM}$ $\mathrm{MgCl}_{2}, \mathrm{pH} 73$ ) and was pumped through the dialysis probe at $10 \mu \mathrm{l} / \mathrm{min}$ using a syringe pump (CMA/100, Carnegie Medicin-Bioanalytical Systems) In order to estımate the CSF concentrations of monoamine metabolites, the recovery of known concentrations of these compounds was determined in vitro for each probe immediately prior to use (Ungerstedt. 1984) After it had been determined that recovery was satısfactory for a given probe $(15-25 \%)$ they were inserted into the lateral ventricle

Chronic dialvsis procedure Animals were lightly anesthetized with ether and the stylet was removed from the guide cannula After the guide cannula was cleared by the insertion of a dummy cannula, the dialysis probe was inserted until the guide cannula contacted the microline tubing The probe was secured in place by the silastic tubing, which fit snugly over the guide cannula To prevent the dialysis probe from being subjected to the torque created when the animal moved, the rat was fitted with a harness that was attached to a liquid commutator by a flexible hollow stainless steel tether (through which the dialysis probe inlet line was fed) Dialysate was collected into $200 \mu$ 1 tubes mounted on the cable just above the harness Samples were collected over $15 \mathrm{~mm}$ in tubes 

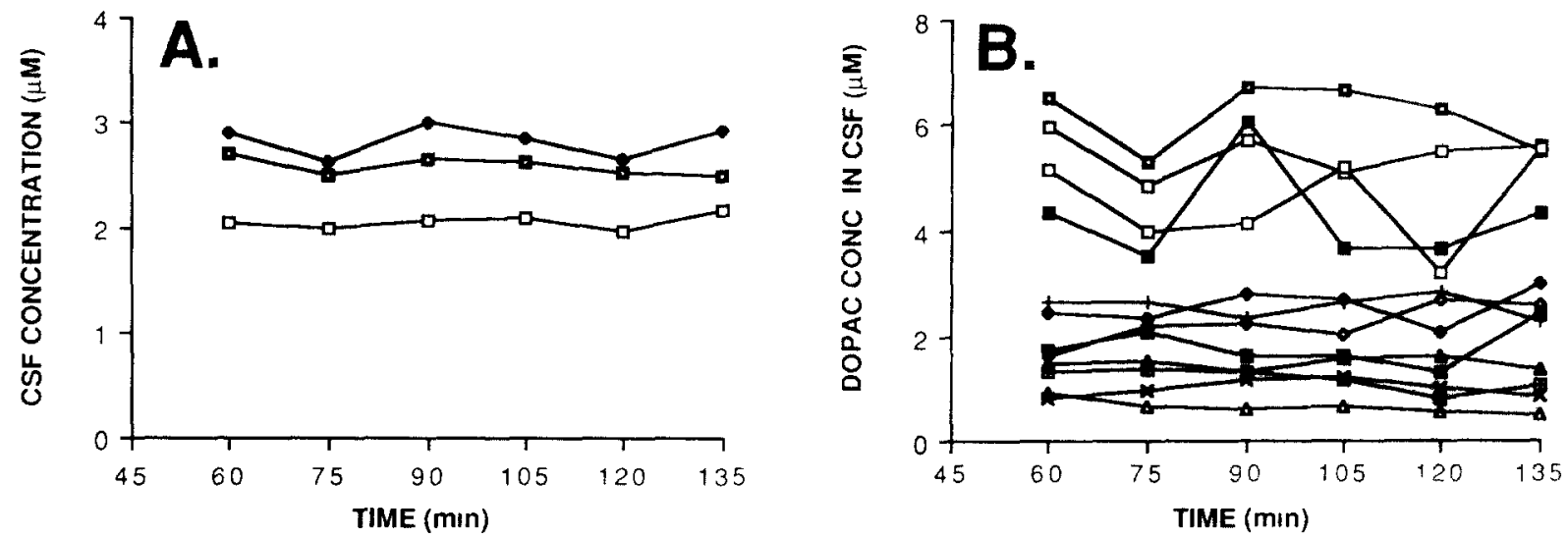

Fig 2 Basal concentrations $(\mu \mathrm{M})$ of monoamine metabolites in CSF (corrected for recovery) determined from in vivo microdialysis Samples were collected over $15 \mathrm{~min}$ intervals for $90 \mathrm{~min}$ with a flow rate of $1 \mu \mathrm{l} / \mathrm{min}$ A average basal concentrations of DOPAC (solid squares), 5-HIAA (diamonds) and HVA (open squares) in CSF ( $n=12$ ) B concentrations of DOPAC in CSF for individual animals contributing to the means depicted in A (above)

containing $15 \mu \mathrm{l}$ of a stabilizing solution $(005 \mathrm{M}$ $\mathrm{HClO}_{4}$ with $2 \mathrm{mM}$ EDTA, $01 \mathrm{mM}$ metabisulfite and $40 \mathrm{pg} / \mu \mathrm{l}$ of dihydroxybenzylamine (DHBA) as an internal standard) Concentrations of monoamine metabolites in the dialysate were measured by HPLC-EC (Becker et al, 1984) All values for CSF concentrations of monoamine metabolites were corrected for probe recovery as determined in vitro At the end of the dialysis procedure, the probe was removed and the guide cannula was resealed with the stylet At the conclusion of the experıment, striatal tıssue was assayed for DA content by HPLC-EC (Robinson et al, 1982), all lesions were $>95 \%$ DA depletion

Acute dialysis procedure Anımals were anesthetized with ethyl urethane $(2000 \mathrm{mg} / \mathrm{kg}, 1 \mathrm{p})$ and dialysis probes were inserted into the lateral ventricle using standard stereotaxic procedure The probes were cemented in place with dental acrylic After the dental acrylic had hardened, animals were removed from the stereotaxic apparatus and body temperature was maintained at $37^{\circ} \mathrm{C}$ with a Deltaphase isothermal heating pad Preliminary experiments indicated that injury-induced release had subsided in anesthetized animals by this time Samples were collected (as described above) as soon as animals were removed from the stereotaxic instrument and body temperature was stable Animals did not recover from anesthesia following the acute procedure, striatal tissue was assayed for DA content as described above

\section{Materials}

All stainless steel tubing was obtained from Small Parts (Miami, FL) Microline tubing was obtained from Cole-Palmer Instrument (Chicago, IL) Silastic tubing was obtained from Dow Corning (Midland, MI) Dialysis tubing (H1P3-20) was obtained from Amicon (Danvers, MA) Epoxy used was made by Devcon (Danvers, MA) All chemicals used were HPLC grade or reagent grade Standards for monoamines and metabolites were obtained from Sigma (St Louis, MO)

\section{Statistics}

Data were analyzed by analysis of variance and subsequent pairwise comparisons using Stat View $512+$ on a Macintosh Plus

\section{Results}

Experiment 1 Basal efflux of monoamine metabolites into $C S F$

After waiting $1 \mathrm{~h}$ for injury-induced release to subside samples were collected at $15 \mathrm{~min}$ intervals As illustrated in Fig 2A, the average concentra- 


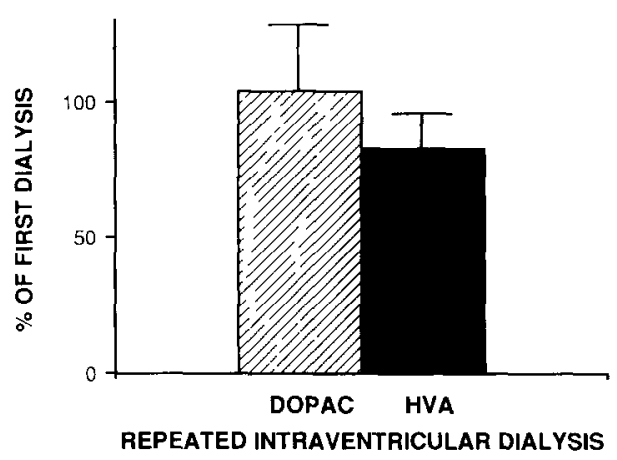

Fig 3 Variability in CSF concentrations of DOPAC and HVA dcross two dialysis sessions separated by 2-6 weeks Baselıne concentrations (mean of 6 baselıne dialysis samples collected as described in legend to Fig 2) obtained during the second dialysis session are expressed as a percent of the first session (no change $=100 \%$ ) Bars indicate the standard error of the mean

tıons of DOPAC, HVA and 5-HIAA in the CSF remained relatively constant over the $90 \mathrm{~min}$ period There was, however, considerable individual variation in monoamine metabolite concentratıons, as illustrated in Fig 2B For 8 of 12 anımals, DOPAC values were within a fairly close range $(065 \pm 006$ to $258 \pm 021 \mu \mathrm{M}$, individual anımal means \pm S E M ), but in 4 other animals DOPAC values were significantly higher than this (4 $265 \pm$ 0366 to $6177 \pm 0251 \mu \mathrm{M})$ Similar individual variation was found for HVA and 5-HIAA Animals with higher concentrations of one monoamine metabolite also tended to have higher concentrations of the other two metabolites The correlation between DOPAC and HVA concentrations was $r=0833 \quad(P<0005)$ and between DOPAC and 5-HIAA $r=0832(P<0005)$ Interestingly, the highest correlation was between the concentrations of HVA and 5-HIAA ( $r=$ 0 999. $P<0$ 001)

In 5 animals the dialysis procedure was repeated 2-6 weeks later and the mean concentratıons of DOPAC and HVA in 6 baseline samples were compared across the two test sessions In Fig 3 the mean baseline release rate during the second dialysis session is expressed as a percent of the first test session There was no significant effect of test session on the concentrations of DOPAC and HVA in the CSF

\section{Experiment 2 DA turnover}

To estımate the rate of brain DA turnover, the accumulation of total DA metabolites was measured after probenecid treatment After obtaining one dialysis sample to determine baseline concentrations in the CSF, anımals received probenecid $(200 \mathrm{mg} / \mathrm{kg}, 1 \mathrm{p})$ and samples were collected over $20 \mathrm{~min}$ intervals for $1 \mathrm{~h}(n=3)$ Samples were collected with $03 \mathrm{M} \mathrm{HClO}_{4}$ replacing the $005 \mathrm{M} \mathrm{HClO}_{4}$ in the stabilizing solution and with the addition of dithiothreitol $(01 \mathrm{mM})$ to the stabilızing solution Half of each sample was assayed for TOTAL DOPAC and HVA after heating at $90^{\circ} \mathrm{C}$ for $45 \mathrm{~min}$ to hydrolyze conjugated metabolites (adapted from the method of Nagel and Schumann, 1980) Conditions were modified to achieve the highest concentrations of DOPAC and HVA in dialysate samples after hydrolysis and MHPG $\mathrm{SO}_{4}$ was included in each sample to verify that hydrolysis had occurred The other half of each sample did not undergo hydrolysis and was assayed for free (1 e not conjugated) DOPAC + HVA The 5-HIAA in standards was not stable under the conditions of the hydrolysis, so values for 5-HIAA are not reported

As illustrated in Fig 4, there is a rapid accumulation of TOTAL DOPAC + HVA (free + conjugated metabolites) following probenecid

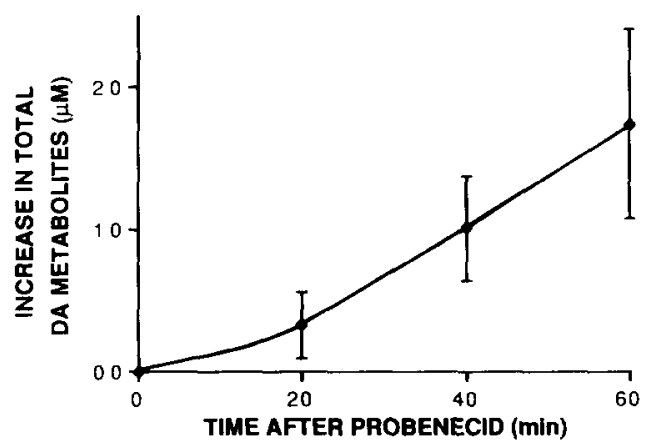

Fig 4 The probenecid-dependent accumulation of DA metabolites in the CSF Probenecid $(200 \mathrm{mg} / \mathrm{kg})$ was injected at tıme zero Dialysate underwent acid hydrolysis to remove conjugated groups from DOPAC and HVA (see text for detalls) and the increase in TOTAL DOPAC + HVA in each of 3 successive $20 \mathrm{~min}$ samples is illustrated (TOTAL DOPAC + HVA in the baseline sample (tume zero) was subtracted from values after probenecid, bars indicate $\pm S E M$ ) 
blockade of acidic metabolite efflux There was also a significant elevation in the CSF concentrations of free DOPAC and HVA after probenecid administration $(P=0006)$ In addition, the amount of TOTAL DOPAC or HVA was greater than values obtained for the non-hydrolyzed samples indicatıng that conjugated DOPAC and HVA
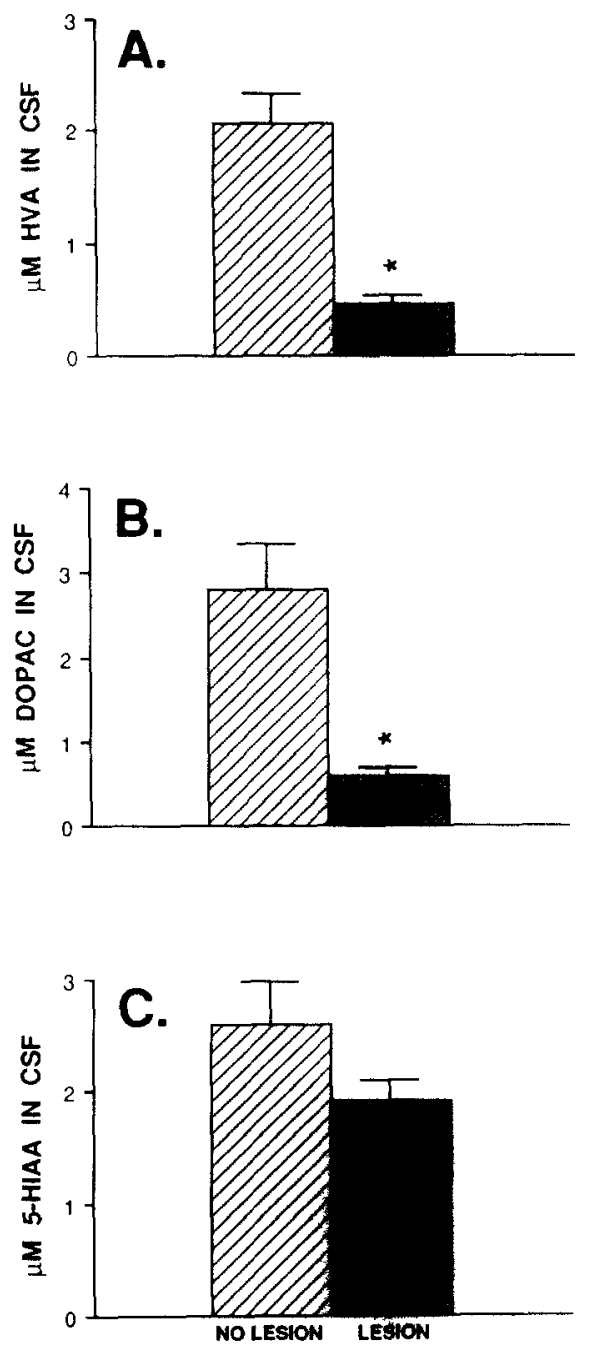

Fig 5 The effect of a unilateral 6-OHDA lesion of the substantia nugra on CSF concentrations of the monoamine metabolites HVA (A), DOPAC (B) and 5-HIAA (C) Each bar represents the mean $\pm S E M$ from 12 animals Samples were obtained from the lateral ventricle of animals with no lesion (hatched bars) and from the lateral ventricle upslateral to a unilateral 6-OHDA lesion (darker hatched bars) * Differs from animals with no lesion $(P<0001)$ are also collected in dialysate from the lateral ventricle For example, the concentration of free DOPAC was $150 \pm 042 \mu \mathrm{M}$ while the concentrdtion of TOTAL DOPAC was $252 \pm 083 \mu \mathrm{M}$ ( $P$ $<0005$ )

Experiment 3 The influence of 6-OHDA lesions on $C S F$ concentrations of monoamine metabolites

Baseline concentrations of monoamine metabohites in the lateral ventricle, ipsilateral to a 6OHDA lesion $(n=12)$, were significantly lower than in animals without lesions $(n=12$, Fig 5) DOPAC concentrations in the lateral ventricle adjacent to a DA-depleted striatum were $79 \%$ lower and the HVA concentrations $78 \%$ lower than in control anımals The basal concentrations of 5-HIAA were not significantly affected by a unilateral 6-OHDA lesion (Fig 5C)

\section{Experiment 4 Haloperidol-induced increase in CSF concentrations of $D A$ metabolites}

Chronic dialysis procedure After a 45 min stabilization period, CSF concentrations of DOPAC and HVA were measured bilaterally in freely moving anımals Baselıne concentrations (mean of two 20 min samples) of DOPAC and HVA were signufiantly lower on the DA-depleted side than contralateral to the lesion (all anımals had $>95 \%$ DA depletion) The percent decrease (lesioned side compared to the non-lesioned side) in DOPAC was $5835 \pm 802 \%(P=00084)$ and for HVA, $5481 \pm 1239 \%(P<0001)$ In response to haloperidol $(2 \mathrm{mg} / \mathrm{kg})$ the CSF concentrations of DOPAC and HVA increased at the same rate on both the lesion and intact sides as indicated by a significant effect of both side and time with no interaction (effect of side $F_{15}=1601, \mathrm{P}<0001$, time $F_{15}=302, P=0013$, side $\times$ time interaction $F_{5132}=0581, P=071$, Fig 6)

Acute dialysis procedure In urethane-anesthetized anımals with unilateral 6-OHDA lesions (> 95\% DA depletion) the baseline concentrations of DOPAC + HVA in the CSF were $822 \pm 39 \%$ lower on the lesioned side than on the intact side There was not a statistically significant asymmetry in baseline (or stımulated) concentrations of DOPAC and HVA in the sham operated controls (mean different in basal concentrations between 

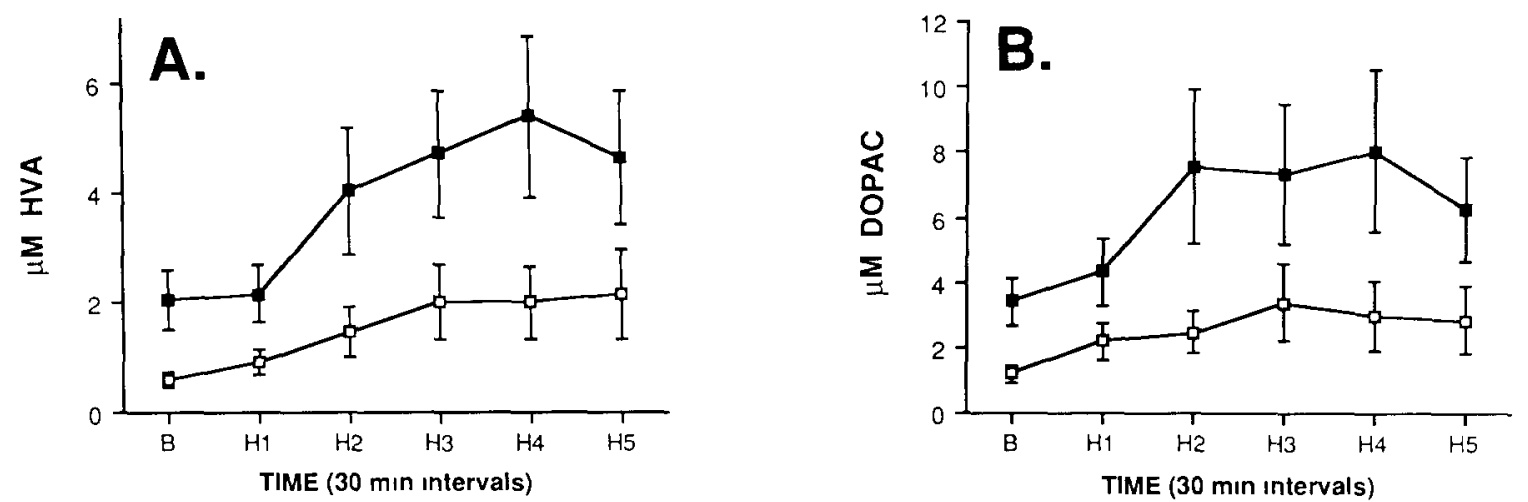

Fig 6 Halopendol-induced increase in CSF concentrations of DA metabolites CSF concentrations of DA metabolties were measured bilaterally in freely moving rats with a unilateral 6-OHDA lesion of the substantia nigra during baseline (B, mean of two 20 min samples) and following haloperidol ( $2 \mathrm{mg} / \mathrm{kg}, \mathrm{H1}-\mathrm{H} 5$ samples were collected over $30 \mathrm{~min}$ ) Probe adjacent to intact striatum closed symbols Probe adjacent to DA depleted stratum open symbols A HVA concentration $(\mu \mathrm{M})$ in CSF (mean \pm S $\mathrm{M}$, $n=12$ ) B DOPAC concentrations in CSF

the two sides $211 \pm 207 \%$ ) and therefore the values were averaged for comparison with 6-OHDA lesion group

As would be predicted from the results in freely moving animals, DOPAC and HVA concentrations in CSF increased bilaterally following haloperidol treatment $(05 \mathrm{mg} / \mathrm{kg})$ in animals with 6-OHDA lesions $\left(F_{110}=2943, P<0005\right.$, Fig 7) However, there was also a significant side $X$ tıme interaction $\left(F_{110}=1886, P=00015\right)$, ind1cating that the rate of the halopendol-induced increase in DOPAC + HVA was greater on the no lesion side than on the lesion side (F1g 7)

Interestingly, in the animals with 6-OHDA lesions, the response of the intact side to haloperidol was also different from that of the non-lesioned control animals $\left(F_{116}=566, P<003\right.$, main effect. $F_{116}=3886, P=0066$, interaction) Haloperidol elevated DOPAC + HVA concentrations on the intact side of animals with 6-OHDA lesions to a greater extent than in control anımals with no lesion $(P<003$, Fig 7$)$

Experiment 5 Baseline concentrations of monoamine metabolites in the CSF of animals before and after adrenal medulla or control grafts

In 18 freely moving rats with unilateral 6OHDA lesions of the substantia ngra baselıne measures of DA metabolites in the CSF were obtained as described above Following the dialy- sis procedure, anımals received grafts of adrendl chromaffin cells or adrenal cortex tissue Adrend medulla tissue from 2 donor rats of the same strain $(n=7)$ or an equal volume of adrenal cortex tissue $(n=8)$ was inserted into the lateral ventricle via a chronically implanted cannula aimed at the

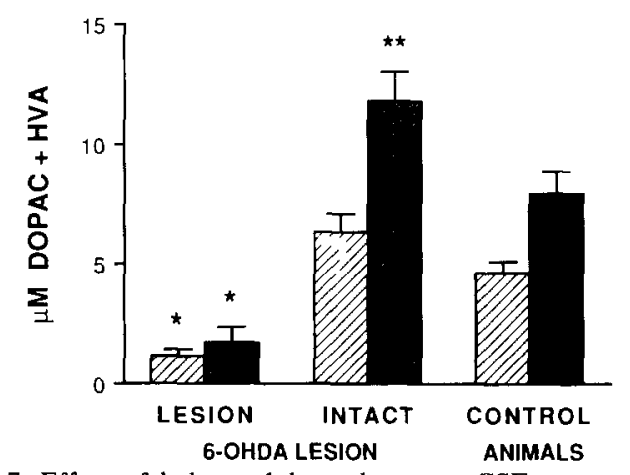

Fig 7 Effect of halopendol on the mean CSF concentration $(\mu \mathrm{M})$ of DOPAC + HVA in urethane anesthetized anımals with a unilateral 6-OHDA lesion of the substantia nigra $(n=6)$ and in control animals $(n=6)$ In animals with 6-OHDA lesions values are given for both the side ipsilateral to the lesion (Lesion) and contralateral to the lesion (Intact) Values from the two hemispheres were pooled for the no lesion controls (control anumals) BASAL EFFLUX, hatched bars, PEAK EFFLUX POST-HALDOL darker hatched bars * Significantly less than the concentrations of DOPAC + HVA in CSF from the lateral ventricle adjacent to the intact side ** The halopendol-induced increase in DOPAC + HVA was significantly greater than control values on the intact side $(P<005)$ 


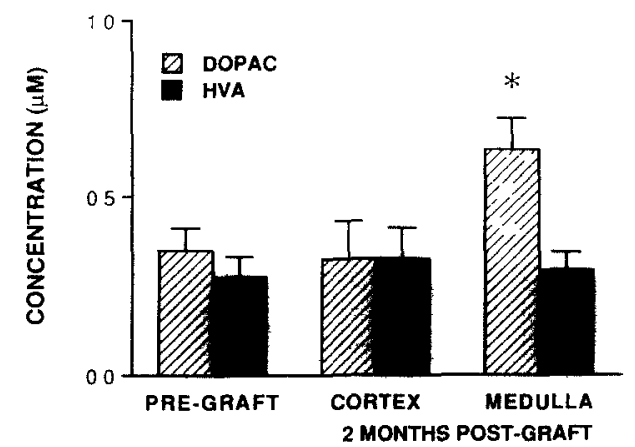

Fig 8 The concentrations of DOPAC and HVA in the CSF $(\mu \mathrm{M}$ ) of anımals prior to (PREGRAFT, $n=18$ ) and 2 months after intraventricular grafts of etther adrenal cortex tissue (CORTEX, $n=8$ ) or adrenal medulla tissue (MEDULLA, $n=7)$ * There was a significant increase in CSF concentratıons of DOPAC $(P<002)$ in animals with adrenal medulla grafts compared to either pregraft values or to values obtained from the CSF of control anımals Bars indicate the standard error of the mean

rostral horn ( 3 animals did not complete the experiment for vanous reasons) Two months after the adrenal tissue had been implanted, the dialysis procedure was repeated

There was a significant increase in the baseline concentrations of DOPAC in the CSF of animals with adrenal medulla grafts $(P<002)$ but no change in the concentration of HVA compared to pregraft values ( $\left.F_{1 g} 8\right)$ In contrast, there was no change in the CSF concentrations of DOPAC or HVA in animals with control grafts of adrenal cortex tissue The concentration of DOPAC in the CSF of animals with adrenal cortex grafts was not different from pregraft values and significantly lower than the concentrations of DOPAC in the CSF of animals with adrenal medulla grafts $(P<$ 0 02)

\section{Discussion}

Microdialysis in the lateral ventricle is a simple and reliable new method for the determination of CSF concentrations of monoamine metabolites in freely moving animals The baseline concentrations of these metabolites were found to be stable both within a $90 \mathrm{~min}$ test session and between test sessions separated by weeks to months The method was also shown to be sensitive to local changes in monoamine metabolite concentratıon induced by a unilateral lesion, by changes in DA activity produced by pharmacological agents, or following implantation of adrenal medulla gratts

The baseline concentrations of monoamine metabolites in CSF estımated by microdialysis were very close to values reported for CSF withdrawn from the lateral ventricle of anesthetized rats For example, Mignot and Laude (1985) reported DOPAC concentrations to be $128 \pm 017$ $\mu \mathrm{M}$ (mean $\pm \mathrm{SEM}$ ), HVA $096 \pm 024 \mu \mathrm{M}$, and 5-HIAA $183 \pm 028 \mu \mathrm{M}$ In comparison, the mean $\pm \mathrm{S} \mathrm{E} \mathrm{M} \mathrm{values} \mathrm{from} \mathrm{Experiment} 1$ reported here were $283 \pm 022 \mu \mathrm{M}$ DOPAC, $205 \pm 011$ $\mu \mathrm{M}$ HVA, and $205 \pm 011 \mu \mathrm{M} 5$-HIAA It is important to note that the values reported here were corrected for the rate of recovery, determined for each dialysis probe prior to use If values had not been corrected for recovery they would be 5-7 times lower (recovery was 15-25\%) than those seen in CSF samples In addition, the rate of DA turnover determined here also agrees with values obtained by other methods of sampling CSF These results suggest that the rate of recovery estumated in vitro provides a good index of the rate of recovery obtained in vivo

The finding that unilateral 6-OHDA lesions of the substantia nigra result in a unilateral decrease in lateral ventricle CSF concentrations of DOPAC and HVA (with no change in 5-HIAA) illustrates the potential of this technique for measurements of regional variability in dopaminergic or serotonergic activity However, it should be pointed out that even though animals had $>95 \%$ DA depletion in the striatum the decrease in DOPAC and HVA in the CSF of freely moving anımals was less than $60 \%$ A similar finding has been reported by Hutson and Curzon (1986), who found that in freely moving anımals with bilateral striatal DA depletions of $68 \%$, the cisterna magna CSF concentrations of DOPAC + HVA were decreased by only $30 \%$ In contrast, we also found that when CSF concentrations were measured b1laterally in urethane-anesthetized animals the decrease in CSF concentrations of metabolites (82 2 $\pm 39 \%$ ) was much closer to the decrease in striatal DA concentrations $(968 \pm 138 \%)$ However, the 
striatal DA depletion was stıll signıficantly greater $(P<001)$ than the depletion in the CSF concentratıons of DA metabolites

There are a number of factors that could account for the difference in the effect of 6-OHDA lesions on striatal DA concentrations vs CSF concentrations of DA metabolites The relatively high concentrations of metabolites in CSF could reflect the contribution of extrastriatal DA neurons to metabolites in the CSF, as suggested by Hutson and Curzon (1986) This idea is not supported, however, by preliminary results from this lab In a subset of the animals that contributed to this report, we measured the concentration of DA in the nucleus accumbens plus olfactory tubercle $($ ACC + TUB $)$ in addition to striatum There was not a significant correlation between the percent difference in the concentrations of DA metabolites in the CSF ((intact - lesion)/intact $\times 100 \%)$ and the percent difference in striatal $(r=0411)$ or $\mathrm{ACC}+\mathrm{TUB}(r=0445) \mathrm{DA}$ concentrations For example, in one animal with a $998 \%$ DA depletion in striatum and a $939 \%$ depletion in ACC + TUB, the CSF concentration of DOPAC + HVA on the lesioned side was only decreased by $352 \%$ compared to the intact side In contrast, the anımal with the greatest decrease in CSF concentrations of DOPAC + HVA (81 5\%) had a $962 \%$ DA depletion in striatum (the smallest lesion in this group of animals) and only a $424 \%$ depletion in ACC + TUB Therefore, CSF concentrations of DA metabolites in the lateral ventricle do not simply reflect the tissue concentrations of DA in adjacent brain regions, but further investigation is required to determine their origin

Another possible explanation for the relatively high concentrations of dopamine metabolites in CSF ipsilateral to a 6-OHDA lesion is that there is increased activity in the remaining DA neurons on the lesioned side This idea is supported by the results of a related microdialysis study Animals with unilateral 6-OHDA lesions have relatively normal concentrations of DA in striatal extracellular fluid on the lesioned side, even when that side is depleted up to $99 \%$ (Robinson and Whishaw, 1988) The normalization of extracellular DA in striatum following recovery from a lesion is probably due to a number of compensatory responses, including an increase in DA synthesis and release from the remaining terminals, and the loss of DA reuptake sites (Heft 1 et al, 1985, Robinson and Whishaw, 1988, Zigmond et al, 1986) It is poss1ble, therefore, that the concentrations of DA metabolites in the CSF reflect in part this compensatory increase in the activity of the remaining DA neurons in the striatum

In urethane-anesthetized anımals the haloper1dol induced increase in DA metabolites was potentiated $\mathrm{in}$ the ventricle contralateral to a 6OHDA lesion, compared to the response in sham-operated control anımals This suggests that a unilateral 6-OHDA lesion alters dopaminergic activity in the striatum both on the side contralateral to the lesion as well as the lesioned side (Fig 7) The idea that there is increased dopaminergic activity in the striatum contralateral to a 6-OHDA lesion is generally consistent with the concept of reciprocal regulation of the two nigrostriatal DA systems and the observation that a nigral lesion results in increased DA release from the contralateral striatum (Nieoullon et al, 1977, Robinson and Whishaw, 1988, Zetterstrom et al, 1986) This interpretation is dlso consistent with reports that unilateral damage to the nigrostriatal DA system results in a persistent decrease in the spontaneous activity of striatal cells on the side contralateral to the lesion (Garcia-Rill et al, 1980, Hull et al, 1974), and with behavioral evidence for a small down-regulation of DA receptors on that side (Costall et al, 1983)

Finally, in anımals with adrenal medulla grafts, there was an increase in the baseline concentrdtions of DOPAC compared to either pre-graft or control graft concentrations of DOPAC whereds there was no change in the baseline concentration of HVA These findings illustrate that with this method, concentrations of monoamine metabolites in the CSF are stable over time following control manipulations In addition selective changes in CSF concentrations of these metabolites can be detected following implantation of a catecholamine secreting tissue Interestıngly, in animals with adrenal medulla grafts, DA was not detected in the CSF (norepinephrine and eptnephrine were also not detectable) These results 
will be reported in greater detall elsewhere (Becker and Freed, 1988)

In conclusion, the use of microdialysis to measure CSF concentrations of monoamine metabolites in freely moving rats provides a valuable new technique for exploning the relations between brain activity and the neurochemical constituents of the CSF This method allows the CSF to be continuously sampled without the introduction or withdrawal of fluids, and it can be used to easily sample multiple regional sites simultaneously

\section{Acknowledgements}

We would like to thank $\mathrm{CJ}$ Moore, $\mathrm{K} \mathrm{M}$ Bentgen and $\mathrm{J}-\mathrm{H}$ Cha for their technical assistance This research was supported by a grant from the NIH to J B B (NS22157) The development of the dialysis system was supported in part by grants from the $\mathrm{HH}$ Rackham Graduate School and the Scottish Rite to TER We thank Merrell-Dow Pharmaceuticals for the gift of the desımıpramıne Dr Becker is supported by Research Career Development Award NS01056 Dr Robınson is supported by Research Career Development Award NS00844

\section{References}

Becker, J B and Freed, W J (1988) Neurochemical correlates of behavioral changes following intraventricular adrenal medulla grafts intraventricular dialysis in freely moving rats, Prog Brain Res, in press

Becker, J B , Castañeda, E, Robinson, T E and Beer, M E (1984) A simple in vitro technique to measure the release of endogenous dopamine and dihydroxyphenylacetic acid from striatal tissue using high performance liquid chromatography with electrochemical detection, $\mathbf{J}$ Neurosci Methods, $11 \quad 19-28$

Costall, B, Kelly, M E and Naylor, R J (1983) Does contralateral circling involve action of drugs on hyposensitive striatal dopamine receptors in the hemisphere contralateral to denervation?, Neuropharmacology, 22 295-302

De La Riva, C F and Yeo, J A G (1985) Repeated determunation of cerebrospinal fluid amine metabolites by automated direct sampling from an implanted cannula in freely moving rats, J Neurosc Methods, 14 233-240

Garcia-Rıll, E, Hull, C D, Cherubinı, E, Levine, M S and Buchwald, N A (1980) The spontaneous firing patterns of forebrain neurons, $V$ Time course of changes in caudat unit activity following dopamıne-depleting lesions Bran Res 190 415-424

Heftı F Enz A and Melamed, E (1985) Partıdl lesions in the nigrostriatal pathway in the rat Acceleration of transmitter synthesis and release of surviving dopaminergic neurones by drugs Neuropharmacology $24 \quad 19-23$

Hull, C D Levine, MS Buchwald, N A, Heller A and Browing, R A (1974) The spontaneous firing pattern of forebrain neurons $I$ The effects of dopamine and non-dopamine depleting lesions on caudate unit firing patterns Brain Res, 73 241-262

Hutson, P H and Curzon, $\mathrm{G}$ (1986) Dopamine metabolites in rat cisternal cerebrospinal fluid major contribution from extrastriatal dopamine neurones, J Neurochem 46 $186-190$

Hutson, P H , Sarna, G S, Kantamanen, B D , and C urzon G (1984a) Concurrent determunation of brain dopamine and 5-hydroxytryptamine turnovers in individual freely moving rats using repeated sampling of cerebrospinal fluid $J$ Neurochem, 43 151-159

Hutson, P H, Sarna, G S and Curzon, G (1984b) Determination of daily variations of brain 5-hydroxytryptamine and dopamine turnovers and of the clearance of their acidic metabolites in conscious rats by repeated ampling of cerebrospinal fluid, J Neurochem, 43 291-293

Kornhuber, M E, Kornhuber, J and Cimniak, L (1986) A method for repeated CSF sampling in the freely moving rat J Neurosc1 Methods, 17 63-68

Mignot E and Laude, D (1985) Study of dopamine turnover by monitorng the decline of dopamine metabolites in rat CSF after alpha-methyl-para-tyrosine, J Neurochem 45 $1527-1533$

Nagel $M$ and Schumann, H -J (1980) A sensitive method for determination of conjugated cetacholamines in biood plasma, J Clin Chem Clin Brochem 18 431-432

Nielsen J A and Moore, KE (1982) Effects of chloral hydrate, gamma-butyrolactone, and equithesin on the efflux of dopamine and 5-hydroxytryptamne metabolites into cerebroventricular perfusates of rats $J$ Neurochem, 39 235-238

Nielsen, J A and Moore, K E (1983) 6-Hydroxydopamine and 5,7-dihydroxytryptamıne metabolites in cerebroventricular perfusates of rats, Pharmacol Brochem Behav 19 905-907

Nielsen, J A, Chapin, DS and Moore, K E (1983) Different1al effects of d-amphetamine, $\beta$-phenylethylamine, cocane and methylphenidate on the rate of dopamine synthesis in terminals of nigrostriatal and mesolumbic neurons and on the efflux of dopamine metabolites into cerebroventricular perfusates of rats, Life Sc1, 33 1899-1907

Nieoullon, A, Cheramy, A and Glowinski, J (1977) Interdependence of the nigrostratal dopaminergic systems on the two sides of the brain in the cat. Science, $198 \quad 416-418$

Robinson, TE and Whishaw, I Q (1988) Normalization of extracellular dopamine in stratum following recovery from a partial unilateral 6-OHDA lesion of the substantia nigra 
a microdıalysıs study in freely moving rats Brain Res In Press

Robinson T E, Becker J B and Presty, S K (1982) Long-term facilitation of amphetamine-induced rotational behavior and striatal dopamine release produced by a single exposure to amphetamine sex differences, Brain Res 253 231-241

Sarna G S, Hutson, P H Tricklebank, M D and Curzon G (1983) Determination of brain 5-hydroxytryptamıne turnover in freely moving rats using repeated sampling of cerebrospinal fluid J Neurochem $40 \quad 383-388$

Ungerstedt, U (1984) Measurement of neurotransmitter release by intracranıal dialysis In C A Marsden (Ed), Mea- surement or Neurotransmitter Release In Vivo, Wiley New York pp 81-105

Zetterstrom T, Herrera-Marschitz $M$ and Ungerstedt, U (1986) Simultaneous measurement of dopamıne release and rotational behavior in 6-hydroxydopamine denervated rats using intracerebral dialysis Bran Res 376 1-7

Zigmond, M J Stachowiak, M K, Berger, T W and Stricker E M (1986) Neurochemical events underlyıng contınued function despite injury to monoaminergic systems In G M Gilıd, A Gorio and G W Kreutzberg (Eds), Processes of Recovery from Neural Trauma, Exp Brain Res, Suppl 13 119-128 